\title{
Quantitative evaluation of shoulder proprioception 6 months following stroke
}

\author{
Moshera Hassan Darwish', Sandra Ahmed ${ }^{2 *}$, Ahmed Abdelalim² and Abdelaziz Abdelaziz Elsherif ${ }^{1}$
}

\begin{abstract}
Background: Chronic shoulder pain following cerebrovascular stroke (CVS) is a major problem that persists after maximum recovery of motor functions. Such pain has been attributed to altered shoulder joint kinematics causing soft tissue damage.

Aim: Evaluation of shoulder proprioception in the ipsilateral paretic arm and contralateral unaffected side 6 months following cerebrovascular event.

Subject and method: Thirty adult patients (G1) with ischemic strokes ranging from 6 months to 1 year and 30 healthy control (G2) were assessed for shoulder proprioception. Angular displacement error was measured during active and passive repositioning of shoulder external and internal rotation in both patients' shoulders and in control's dominant upper limb.

Results: Statistically significant increase in angular displacement error was found in all tests in the affected shoulder compared to the unaffected contralateral shoulder and dominant arm of control subjects. The contralateral unaffected shoulder of patients showed within normal values and no differences with control values. Passive external and internal rotations showed statistically higher errors in patients with cortical lesions compared to those with subcortical lesions.

Conclusion: Six months following the CVS, shoulder proprioception deficit in the affected hemiparetic side persists. Contralateral side shows no abnormalities. Cortical lesions might be associated with late shoulder proprioception recovery compared to subcortical lesions. The side of the lesion does not seem to affect the severity of proprioception deficit.
\end{abstract}

Keywords: Stroke, Shoulder, Proprioception

\section{Introduction}

Stroke is a global problem with a burden that continues to increase due to population growth and aging [1]. Estimated prevalence of stroke in Egypt is 722/100,000 [2] with a higher prevalence among men and illiterate patients [3] which are by majority manual worker.

Improvement of quality of life (QoL) following stroke occurs up to 6 months following the event [4]. Shoulder pain is a major problem that occurs in nearly third of stroke patients with a majority ranging between moderate and severe degree. It appears around the fourth

\footnotetext{
* Correspondence: sandra.ahmed@kasralainy.edu.eg

${ }^{2}$ Department of Neurology, Faculty of Medicine, Cairo University, Cairo

11562, Egypt

Full list of author information is available at the end of the article
}

month [5] and persists in $21 \%$ of patients 16 months following stroke [6].

The sensorimotor system is defined as all of the sensory, motor, and central integration and processing components involved in maintaining joint stability [7]. Proprioceptive impairment as much as motor deficit is of outmost importance in planning of future management of stroke patients [8]. Chronic post-stroke shoulder pain (PSSP) has been attributed to altered kinematics of the joint leading to secondary soft tissue damage [9]. Rehabilitation of position sense showed promising results to avoid such problem [10].

The aim of this study is to evaluate shoulder proprioception in the ipsilateral paretic arm and contralateral normal side 6 months following the cerebrovascular event. 


\section{Subjects and methods}

This is a case-control study including 30 adults with anterior circulation ischemic cerebrovascular stroke patients (group 1) and 30 control healthy subjects (group 2) matching for age, sex, weight, and height. Patients were recruited from outpatient clinic of neuromuscular disorders and its surgery, Faculty of Physical Therapy, Cairo University. Included patients have stroke for more than 6 months and less than 1 year. The patients should have sufficient cognitive abilities to enable them understanding the requirements of the study. We excluded patients with frozen shoulder or any other orthopedic problems affecting the shoulders, language or hearing deficits, and diabetes mellitus. All patients had an almost equal physiotherapy program prior to the recruitment as they were following the standard program of the physical therapy department of neuromuscular disorders and its surgery, Faculty of Physical Therapy, Cairo University.

Both patients' shoulders were assessed. The power of the affected arm ranged from 3 to $4+$ according to "Medical Research Council Scale (MRC)" and spasticity from 1 to $1+$ according to "Modified Aschworth Scale (MAS)" [11] to assure enough control of the patient over his range of movement. The control group (G2) was examined in the dominant shoulder only. According to brain imaging, patient's lesions were subdivided according to site of the lesion into right or left and cortical ( $n$ $=5)$ or subcortical $(n=18)$. Patients with mixed cortical and subcortical lesions were excluded $(n=7)$.

\section{Primary outcome}

The primary outcome is measuring the angular displacement error during active and passive repositioning of shoulder external and internal rotation. Absolute angular displacement error is defined as the difference in degrees between indicated and reference position during joint position sense assessment [12].

\section{Secondary outcome}

The secondary outcome is finding a possible relation between persistent shoulder proprioceptive deficit and site of the brain lesion.
Table 1 Age, weight, and height of patients (G1) and controls (G2)

\begin{tabular}{lllll}
\hline Variable* & Patients (G1) & Controls (G2) & $t$ value & $P$ value \\
\hline Age (years) & $55 \pm 4.53$ & $54.47 \pm 4.36$ & 0.4644 & 0.6441 \\
Weight $(\mathrm{kg})$ & $84.4 \pm 14.64$ & $81.9 \pm 15.37$ & 0.6450 & 0.5215 \\
Height $(\mathrm{cm})$ & $167.7 \pm 7.9$ & $165 \pm 8.58$ & 1.268 & 0.2098 \\
\hline
\end{tabular}

*The values are expressed by mean \pm SD

\section{Procedure}

Individual shoulder proprioception assessment was done using "Biodex Isokinetic Dynamometer" and Biodex system III Multijoint testing and Rehabilitation System (Biodex, Medical Inc., Shirly, NY). Patient weight, height, and personal data were introduced in the system. Patient was seated with a back tilt $85^{\circ}$, dynamometer orientation $20^{\circ}$, and tilting $50^{\circ}$. Positioning of the patient was done so the axis of rotation of the fulcrum of the dynamometer is corresponding to axis of rotation of the shoulder. Two crossed straps were used to fix the patient to the chair in order to obtain isolated shoulder movement.

Absolute angular error was measured in the following two situations:

\section{Passive reproduction of joint position (passive internal rotation and passive external rotation)}

Each patient was allowed to sense the reference angle of $10^{\circ}$ for $10 \mathrm{~s}$ before performing the test. The tested arm was then passively moved in both directions subsequently, and the patient was asked to press a bottom with his untested hand if he feels that he reached the reference angle.

\section{Active reproduction of joint position (active internal rotation and active external rotation)}

Same procedure as above was used but with the patient moving actively his limb to the reference angle relative to the starting position.

In each position reached by the patient, absolute angle displacement error was obtained by measuring the difference between the reference angle and indicated actual angle. Test was reproduced three times, and the mean of the three readings was considered final angular error.

Table 2 Comparison of angular displacement errors of shoulder joint position sense in affected arm and unaffected arm of patients (G1)

\begin{tabular}{lllll}
\hline Variables* & Affected arm & Unaffected arm & $t$ value & $P$ value \\
\hline Active external rotation & $3.823^{\circ} \pm 2.067$ & $2.72^{\circ} \pm 2.141$ & 2.03 & $0.0469^{* *}$ \\
Passive external rotation & $4.597^{\circ} \pm 3.115$ & $3.18^{\circ} \pm 2.384$ & 2.178 & $0.0376^{* *}$ \\
Active internal rotation & $4.573^{\circ} \pm 2.431$ & $3.007^{\circ} \pm 1.802$ & 3.339 & $0.0023^{* *}$ \\
Passive internal rotation & $3.97^{\circ} \pm 3.546$ & $2.657^{\circ} \pm 2.069$ & 2.077 & $0.0468^{* *}$ \\
\hline
\end{tabular}

*The values are expressed by mean \pm SD

** Statistically significant $(P<0.05)$ 
Table 3 Comparison of angular displacement errors of shoulder joint position sense in the affected arm of patients (G1) and dominant arm of normal subject (G2)

\begin{tabular}{lllll}
\hline Variables* & Patients (G1) & Controls (G2) & $t$ value & $P$ value \\
\hline Active external rotation & $3.823^{\circ} \pm 2.067$ & $2.903^{\circ} \pm 1.378$ & 2.028 & $0.0471^{* *}$ \\
Passive external rotation & $4.597^{\circ} \pm 3.115$ & $2.843^{\circ} \pm 1.959$ & 2.610 & $0.0115^{* *}$ \\
Active internal rotation & $4.573^{\circ} \pm 2.431$ & $2.37^{\circ} \pm 1.402$ & 4.301 & $0.0001^{* *}$ \\
Passive internal rotation & $3.97^{\circ} \pm 3.546$ & $2.327^{\circ} \pm 0.825$ & 2.473 & $0.0164^{* *}$ \\
\hline
\end{tabular}

*The values are expressed by mean \pm SD

** Statistically significant $(P<0.05)$

Written consent was obtained from each patient after thorough explanation of the procedure, and the study was approved by the local ethical committee of Faculty of Physical Therapy, Cairo University.

\section{Statistical analysis}

The statistical analysis was done using the Statistical Package of Social Science Software program, version 21 (SPSS, IBM Inc., Chicago, IL). The descriptive data were summarized using the arithmetic mean and the standard deviation for quantitative variable and the frequency percentage for qualitative variables. Comparison of the data within the same group was done using the paired $t$ test and between groups using the unpaired $t$ test.

\section{Results}

Patient group (G1) and control group (G2) age, weight, and height were matched as seen in Table 1 . There was male predominance in both groups with almost equal proportion (males/females) (G1; $n=23 / 7, \mathrm{G} 2 ; n=21 / 9$ ).

Comparison of angular displacement error in affected and unaffected shoulder of G1 showed a statistically significant difference (Table 2). Comparison of the affected shoulder of patients (G1) and the dominant shoulder of controls (G2) showed a statistical significant difference in all tests (Table 3). No difference was found between the unaffected shoulder of G1 and the tested shoulder of G2 (Table 4).

According to brain imaging, patients were subdivided into those with cortical lesions $(n=5)$ and patients with subcortical lesions $(n=18)$. Comparison of both subgroups

Table 4 Comparison of angular displacement errors of shoulder joint position sense in the unaffected arm of patients (G1) and dominant arm of normal subject (G2)

\begin{tabular}{lllll}
\hline Variables* & Patients (G1) & Controls (G2) & $t$ value & $P$ value \\
\hline Active external rotation & $2.72^{\circ} \pm 2.141$ & $2.903^{\circ} \pm 1.378$ & 0.3944 & 0.6948 \\
Passive external rotation & $3.18^{\circ} \pm 2.384$ & $2.843^{\circ} \pm 1.959$ & 0.5976 & 0.5524 \\
Active internal rotation & $3.007^{\circ} \pm 1.802$ & $2.37^{\circ} \pm 1.402$ & 1.527 & 0.1322 \\
Passive internal rotation & $2.657^{\circ} \pm 2.069$ & $2.327^{\circ} \pm 0.825$ & 0.8116 & 0.4204 \\
\hline *The values are expressed by mean \pm SD & & &
\end{tabular}

showed a statistically significant increase in angular errors in patients with cortical lesions in passive external and internal rotation (Table 5).

Subgroups with left, right, or bilateral lesions showed no statistical difference in degree of angular error of the affected arm in both active and passive external or internal rotations $(P>0.05)$.

\section{Discussion}

This study demonstrates that shoulder proprioception deficit is an underestimated problem that persists beyond 6 months in paretic arm of stroke patients despite adequate physical therapy. This deficit may be more common in patients presenting with cortical lesions.

The upper limit of age for patients and controls was 63 years. Anatomical and physiological changes of the central and peripheral nervous system affect proprioception with advancing of age $[13,14]$. We chose patients with stroke onset at least 6 months prior to inclusion period as maximum recovery of sensory functions usually occurs within this period [15] although continuous response to rehabilitation programs was shown to extend beyond this limit of time [16].

Patient group (G1) with cerebrovascular stroke (> 6 months) had an increased absolute angular displacement error in all tested positions (active external rotation, passive external rotation, active internal rotation, and passive internal rotation) when compared to unaffected contralateral arm and same aged control group (G2) $(P>0.05)$. Niessen et al. showed similar results when he compared proprioception of the shoulder in the paretic arm compared to controls [12]. Yet he showed that the contralateral arm as well was affected to some extent unlike our

Table 5 Comparison between patients with cortical and subcortical lesions in angular errors of the affected arm

\begin{tabular}{llll}
\hline Action* & Cortical $(n=5)$ & Subcortical $(n=18)$ & $P$ value \\
\hline Active external rotation & $4.2^{\circ} \pm 2.38$ & $3.56^{\circ} \pm 2.38$ & 0.88 \\
Passive external rotation & $5.8^{\circ} \pm 4.76$ & $4.28^{\circ} \pm 2.67$ & $0.009^{* *}$ \\
Active internal rotation & $4.4^{\circ} \pm 2.88$ & $4.44^{\circ} \pm 2.43$ & 0.408 \\
Passive internal rotation & $7.6^{\circ} \pm 6.54$ & $3.2^{\circ} \pm 2.51$ & $0.000^{* *}$
\end{tabular}

*The values are expressed by mean \pm SD

**Statistically significant $(P<0.05)$ 
results that shows no affection of the contralateral side. This difference can be attributed to the time of testing; he chose patients with sub-acute stroke, but our patients were assessed 6 months following stroke. This time lapse can be sufficient for contralateral recovery but not for the paretic side. Normal function of the shoulder was stated to depend on shoulder stability; static stabilization that depends on capsulolabral complex and dynamic stabilization that depends on scapulo-thoracic and glenohumeral muscles both coordinated by neuromuscular control [17]. Gooey et al. [18] showed that the muscle spindle is the outmost important structure in determining joint position. The shoulder seems to contain very few mechanoreceptor [19] that is why Neissen et al. [12] said that the kinesthetic deficit in stroke patients is primarily due to gamma motor neuron dysfunction of muscle spindles sensitivity so there is a delay in detection of muscle stretch, thus creating the cascade of shoulder instability, soft tissue injury, and chronic pain [9].

Angular error of passive external and internal rotation of the shoulder was statistically higher in patients with cortical lesions $(n=5)$ compared to patients with subcortical lesions $(n=18)(P=0.009$ and 0.000 respectively). In a previous study, patients with cortical lesions were shown to recover more rapidly than patients with subcortical lesions, yet recovery was used in terms of motor function only [20]. Proprioception deficit seems to be different as it is more linked to cortical sensory integrating regions. Right supramarginal gyrus was proved to play a major role in proprioception loss in stroke patients [21] thus may be explaining prolonged recovery of proprioception in patients with cortical lesions. On the other hand, relation between lesion site (right or left) and proprioceptive deficit was rejected by Dukelow et al. [8], which support our results where no difference was found between site or bilaterality of the lesion and proprioception deficit. Yet the small number used in both studies could not give conclusive results.

\section{Conclusion}

Chronic shoulder proprioceptive deficit persists beyond 6 months following cerebrovascular event but only in the affected paretic arm. This persistence may be linked to cortical lesions rather than subcortical ones. A new perspective in rehabilitation of stroke patients should include an extended program targeting deep sensory system as much as motor system through the first year following the event in order to achieve a better quality of life increasing independency and decreasing chronic debilitating pain.

\section{Abbreviation}

CVS: Cerebrovascular stroke; MAS: Modified Aschworth score; PSSP: Poststroke shoulder pain; QoL: Quality of life

Acknowledgements

Not applicable
Funding

None

Availability of data and materials

The dataset is not publicly available due to institutional rules.

\section{Authors' contributions}

All the authors contributed to the study design. SA and AA selected the cases and did neurological examination of patients. MD and AES did the practical part: shoulder proprioception assessment. Data were pulled by all the authors in one master sheet, and all of them contributed in the paper conception and editing. All authors reviewed and approved the final draft.

Ethics approval and consent to participate

Written consent was obtained from each patient after thorough explanation of the procedure, and the study was approved by the local ethical committee of Faculty of Physical Therapy, Cairo University.

Ethical committee number: 012/00544

Date: 01/06/2014

Consent for publication

Not applicable

Competing interests

The authors declare that they have no competing interests.

\section{Publisher's Note}

Springer Nature remains neutral with regard to jurisdictional claims in published maps and institutional affiliations.

\section{Author details}

${ }^{1}$ Department of Neuromuscular Disorders and its Surgery, Faculty of Physical Therapy, Cairo University, Cairo, Egypt. ${ }^{2}$ Department of Neurology, Faculty of Medicine, Cairo University, Cairo 11562, Egypt.

Received: 4 May 2018 Accepted: 24 October 2018

Published online: 06 November 2018

\section{References}

1. Feigin VL, Mensah GA, Norrving B, Murray CJ, Roth GA, Group GSPE. Atlas of the Global Burden of Stroke (1990-2013): the GBD 2013 study. Neuroepidemiology. 2015;45(3):230-6.

2. Abd-Allah F, Khedr E, Oraby MI, Bedair AS, Georgy SS, Moustafa RR. Stroke burden in Egypt: data from five epidemiological studies. Int J Neurosci. 2018;128(8):765-71.

3. Khedr EM, Elfetoh NA, Al Attar G, Ahmed MA, Ali AM, Hamdy A, et al. Epidemiological study and risk factors of stroke in Assiut Governorate, Egypt: community-based study. Neuroepidemiology. 2013;40(4):288-94.

4. van Mierlo ML, van Heugten CM, Post MW, Hajós TR, Kappelle LJ, VisserMeily JM. Quality of life during the first two years post stroke: the Restore4Stroke cohort study. Cerebrovasc Dis. 2015:41(1-2):19-26.

5. Lindgren I, Jönsson AC, Norrving B, Lindgren A. Shoulder pain after stroke: a prospective population-based study. Stroke. 2007;38(2):343-8.

6. Jönsson AC, Lindgren I, Hallström B, Norrving B, Lindgren A. Prevalence and intensity of pain after stroke: a population based study focusing on patients' perspectives. J Neurol Neurosurg Psychiatry. 2006;77(5):590-5.

7. Myers JB, Wassinger CA, Lephart SM. Sensorimotor contribution to shoulder stability: effect of injury and rehabilitation. Man Ther. 2006;11(3):197-201.

8. Dukelow SP, Herter TM, Bagg SD, Scott SH. The independence of deficits in position sense and visually guided reaching following stroke. J Neuroeng Rehabil. 2012:9:72

9. Niessen $\mathrm{MH}$, Veeger DH, Meskers CG, Koppe PA, Konijnenbelt MH, Janssen TW. Relationship among shoulder proprioception, kinematics, and pain after stroke. Arch Phys Med Rehabil. 2009:90(9):1557-64.

10. Kattenstroth JC, Kalisch T, Kowalewski R, Tegenthoff M, Dinse HR. Quantitative assessment of joint position sense recovery in subacute stroke patients: a pilot study. J Rehabil Med. 2013;45(10):1004-9.

11. Bohannon RW, Smith MB. Interrater reliability of a modified Ashworth scale of muscle spasticity. Phys Ther. 1987;67(2):206-7. 
12. Niessen $\mathrm{MH}$, Veeger $\mathrm{DH}$, Koppe PA, Konijnenbelt $\mathrm{MH}$, van Dieën J, Janssen TW. Proprioception of the shoulder after stroke. Arch Phys Med Rehabil. 2008;89(2):333-8

13. Hughes CML, Tommasino P, Budhota A, Campolo D. Upper extremity proprioception in healthy aging and stroke populations, and the effects of therapist- and robot-based rehabilitation therapies on proprioceptive function. Front Hum Neurosci. 2015;9:120.

14. Wright ML, Adamo DE, Brown SH. Age-related declines in the detection of passive wrist movement. Neurosci Lett. 2011;500(2):108-12.

15. Connell $L A$, Lincoln NB, Radford KA. Somatosensory impairment after stroke: frequency of different deficits and their recovery. Clin Rehabil. 2008;22(8):758-67.

16. Krakauer JW. Arm function after stroke: from physiology to recovery. Semin Neurol. 2005;25(4):384-95.

17. Lubiatowski P, Romanowski L, Kruczyński J, Manikowski W, Jaruga M. Proprioception in pathophysiology and treatment of shoulder instability. Ortop Traumatol Rehabil. 2003:5(4):421-5.

18. Gooey K, Bradfield O, Talbot J, Morgan DL, Proske U. Effects of body orientation, load and vibration on sensing position and movement at the human elbow joint. Exp Brain Res. 2000;133(3):340-8.

19. Ide K, Shirai $Y$, Ito H. Sensory nerve supply in the human subacromial bursa. J Shoulder Elb Surg. 1996:5(5):371-82.

20. Kwakkel G, Kollen BJ, van der Grond J, Prevo AJ. Probability of regaining dexterity in the flaccid upper limb: impact of severity of paresis and time since onset in acute stroke. Stroke. 2003;34(9):2181-6.

21. Ben-Shabat E, Matyas TA, Pell GS, Brodtmann A, Carey LM. The right supramarginal gyrus is important for proprioception in healthy and strokeaffected participants: a functional MRI study. Front Neurol. 2015;6:248.

\section{Submit your manuscript to a SpringerOpen ${ }^{\circ}$ journal and benefit from:}

- Convenient online submission

- Rigorous peer review

- Open access: articles freely available online

- High visibility within the field

- Retaining the copyright to your article

Submit your next manuscript at $\boldsymbol{\nabla}$ springeropen.com 